\title{
Body Mass Index and Dental Caries: A Systematic Review
}

\section{${ }^{1}$ Sahana Shivakumar, ${ }^{2}$ Adit Srivastava, ${ }^{3}$ Ganiga C Shivakumar}

\begin{abstract}
Introduction: This review was undertaken to analyze the relationship between body mass index (BMI) and dental caries with the available literature evidence.

Materials and methods: The articles were searched from Medline/PubMed and Journal of Web published between 2005 and 2016.

Results: Out of the 146 references obtained, 16 articles in English language were read in full, which fulfilled the inclusion criteria after assessing by Down and Black criteria.

Conclusion: No consensus was reached in the relationship between BMI and dental caries in the present review due to varied associations

Keywords: Association, Body mass index, Cross-sectional study, Dental caries, Review.
\end{abstract}

How to cite this article: Shivakumar S, Srivastava A, Shivakumar GC. Body Mass Index and Dental Caries: A Systematic Review. Int J Clin Pediatr Dent 2018;11(3):228-232.

\section{Source of support: Nil}

Conflict of interest: None

\section{INTRODUCTION}

Oral diseases, especially dental caries, are still mainly prevalent in most developing countries, affecting people from all races, socioeconomic status, and ages. This disease, dental caries, still continues to be a public health problem in spite of technological advancements and a better understanding of the carious process. ${ }^{1}$ Dental caries is a multifactorial disease attributed to both modifiable risk factors like dietary factors, water fluoride levels, tooth

\footnotetext{
${ }^{1}$ Reader, ${ }^{2}$ Associate Professor, ${ }^{3}$ Professor

${ }^{1}$ Department of Public Health Dentistry, Babu Banarasi Das College of Dental Sciences, Lucknow, Uttar Pradesh, India

${ }^{2}$ Unit of Oral Medicine and Radiology, Department of Oral Medicine \& Radiology, Faculty of Dental Sciences, Institute of Medical Sciences, Banaras Hindu University, Varanasi, Uttar Pradesh, India

${ }^{3}$ Department of Oral Medicine and Radiology, Babu Banarasi Das College of Dental Sciences, Lucknow, Uttar Pradesh, India

Corresponding Author: Adit Srivastava, Associate Professor Unit of Oral Medicine and Radiology, Department of Oral Medicine \& Radiology, Faculty of Dental Sciences Institute of Medical Sciences, Banaras Hindu University, Varanasi, Uttar Pradesh, India, Phone: +919451525522, e-mail: dr.adit69@ gmail.com
}

brushing frequency, and nonmodifiable risk factors like socioeconomic status and previous caries experience. The focus now is shifted to modifiable factors, specifically diet, in the prevention of dental caries.

Body mass index is an anthropometric measurement which measures weight relative to the height. Though it is often used to estimate the level of body fat in individuals, it provides an excellent indicator of obesity-related health risks.

The world is witnessing an increasing number of overweight individuals owing to the consumption of fast food and soft drinks coupled with lack of activity and exercise. Overweight individuals are associated with prolonged exposure to carbohydrates. ${ }^{2}$ Excessive consumption of refined carbohydrates, especially sugar in its refined form, is associated both with dental caries and being overweight and obese. ${ }^{3}$ An association between BMI and dental caries works probably on this possibility. The Scientific Advisory Committee on Nutrition ${ }^{4}$ (London) reported an association of higher consumption of free sugars with dental caries. The consumption of sugar-sweetened beverages further leads to greater weight gain and increase in BMI.

Literature provides evidence for the coexistence of obesity and dental caries, as they have common risk factors like consumption of free sugars and socioeconomic deprivation. Overweight and dental caries are attributed to complex behavioral and societal factors which include genetic component, increased media exposure through television and computer games, overall calorie intake along with increased intake of sugary foods and beverages, physical activity, habits of both oral hygiene and personal. Various literature stands evidence to the coexistence of the two conditions in the same individuals and populations, but with variations. ${ }^{5-7}$ The review hence, was undertaken with the objective of establishing a scientific relationship between BMI and dental caries.

\section{MATERIALS AND METHODS}

The literature search of published articles was performed in the electronic databases of the Medline/PubMed, and Journal of Web, between 2005 and 2016. Only study articles which investigated the relationship between dental caries and BMI on all ages were looked for, excluding systematic reviews and meta-analysis published. The 


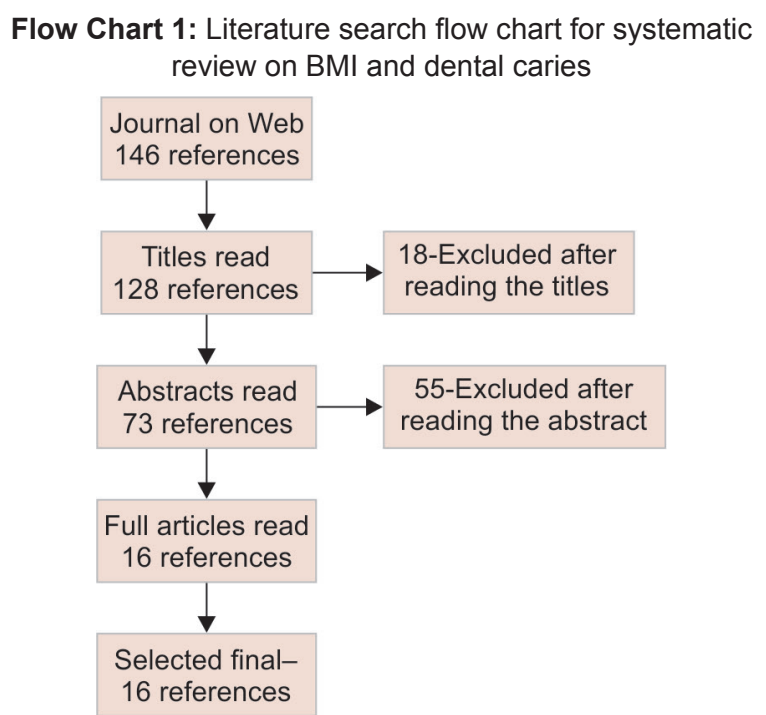

terms used for literature search were dental caries and BMI. Two independent researchers searched the databases and identified 68 relevant studies (Flow Chart 1).

Articles published before 2004, studies done on specific groups, and dissertations were excluded. Downs and Black ${ }^{8}$ criteria were used to assess the quality of scientific evidence in chosen articles. Out of the 27 items criteria, 10 had to be excluded, as it could be applied only for intervention studies and none of the study chosen had an experimental study design. Studies which scored more than 10 items criteria were considered of good scientific evidence. This criterion of fulfilling $50 \%$ or greater items of the Downs and Black ${ }^{8}$ criteria was set by the study authors. No cases of disagreement were reported between the authors for any of the studies researched.

\section{RESULTS}

A total number of 146 reference articles were obtained in Journal of Web, out of which 18 articles were excluded after reading the titles. Out of this, 55 articles were excluded after reading the abstracts, making the count to 73. Finally, 16 full articles in English were included in the review, which met the inclusion criteria of the reviewers.

Table 1 shows the list of studies reviewed on BMI and dental caries. The review presented contradictory reports. While studies conducted by de Jong-Lenters et $\mathrm{al}_{1}{ }^{9}$ Lempert et $\mathrm{al},{ }^{10}$ Sharma et $\mathrm{al}_{1}{ }^{11}$ Martins et $\mathrm{al},{ }^{12}$ Chukwumah et al ${ }_{1}^{13}$ Elangovan et al, ${ }^{14}$ Cinar and Murtomaa, ${ }^{15}$ and Pinto et a ${ }^{16}$ did not report any association between BMI and dental caries, the studies of Creske et al, ${ }^{17}$ Bagherian and Sadeghi, ${ }_{18}^{18}$ Shahraki et al, ${ }^{19}$ Cantekin et $\mathrm{al}^{20}$ Thippeswamy et $\mathrm{al}^{21}$ and Willerhausen et $\mathrm{al}^{22}$ reported a significant association between BMI and dental caries. Studies of Shailee et $\mathrm{al}^{23}$ and Parkar and $\mathrm{Chokshi}^{24}$ revealed a negative correlation between Decayed, extracted, filled teeth (deft) and BMI. Among the 16 studies reviewed, 14 studies employed a crosssectional design, one prospective cohort structure, and one study a case-control design as mentioned in Table 1.

\section{DISCUSSION}

The present review tried to analyze a relationship between BMI and dental caries based on articles published from the period between 2005 and 2016. The results of this systematic review suggest that no consensus has been reached in the various studies included because of varied associations. Out of the 73 abstracts read, 55 were excluded, making the final selected articles to a total of 16. Of the 16 articles reviewed, 14 were cross-sectional studies, 1 case-control study, and 1 prospective cohort study.

The standard way of recording the anthropometric assessment of BMI is done by using a $150 \mathrm{~kg}$ digital scale and $200 \mathrm{~cm}$ tape to measure height according to the World Health Organization (WHO) guidelines. The body weight was recorded by using a standard beam balance scale with participants wearing light dresses and barefoot. Body height is recorded with subjects not wearing any shoes and head touching the ruler with line of sight aligned horizontally. The BMI is calculated by the formula: Weight $(\mathrm{kg}) /$ height $\left(\mathrm{m}^{2}\right)$. The interpretation of the scores are underweight $(<18.5)$, normal weight (18.5-24.99) and overweight ( $>25)$ as per WHO. ${ }^{25}$ The ease of implementation and objectivity makes BMI a popular tool to measure obesity. But, this index is to be considered cautiously, as it can produce false-positive results for the fact that it cannot differentiate between lean body mass and fat mass.

Dental caries diagnosis in most of the studies employed visual examination of the exposed teeth or surfaces. The DEFT index was recorded to measure dental caries in primary dentition and decayed, missing, filled teeth (DMFT) index was used to record dental caries in permanent dentition. But, this method of examination leads itself to underreporting of the disease. Use of interproximal radiographs is more sensitive to caries diagnosis, but not very suitable for epidemiological surveys, as it is both expensive and increases the risk of radiation exposure.

Systematic reviews conducted by several authors ${ }^{26}$ excluded children under 6 years of age, considering the observation of increased intake of cariogenic food in this age group, which poses a significant risk to both dental caries and obesity. Also, parental influence and super- 


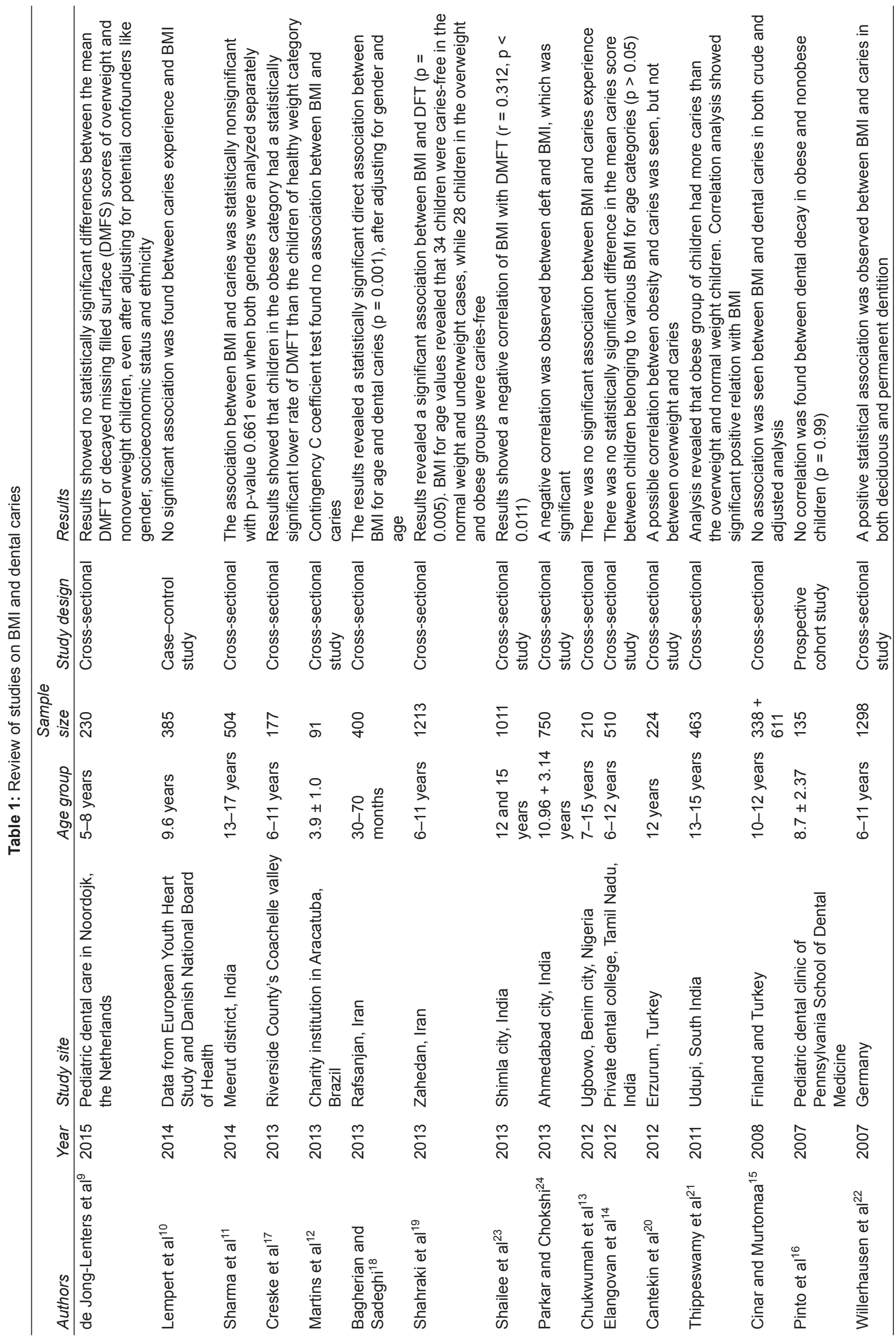


vision on this age group decide the diet pattern, and oral hygiene practices dictate caries prevalence. While parental control on sugar consumption can lower caries experience, lack of control can even increase the chance of caries and, subsequently, obesity. Not excluding any population for the review was in accordance with the study of Kantovitz et al. ${ }^{27}$

The review included studies published in English language only, incorporating an element of selection bias. The variation in the study designs and reporting reflected on the quality of the included articles. Most of the studies reviewed did not consider the various confounding variables like socioeconomic factors, dietary pattern, and oral hygiene practice which could have a played a major role in the establishment of a relationship. Factors to be considered in addition to the above confounders are utilization of oral health services and use of fluoridated substances. These are potential effect modifiers which may result in a weak or negative association between BMI and dental caries. The Downs and Black ${ }^{8}$ instrument used to assess the quality of studies was also employed by other authors ${ }^{26}$ because of its clarity. Though it was originally designed to evaluate intervention studies, it can be employed in observational studies also after excluding certain items.

\section{CONCLUSION}

No agreement was reached on the relationship between BMI and dental caries because of varied associations of the studies reviewed and for not including the effect of confounders and effect modifiers. It is recommended to conduct newer and clearly delineated studies in future to provide valuable clues regarding this relationship.

\section{REFERENCES}

1. Rao A, Sequeria SP, Peter S. Prevalence of dental caries among school children in Moodbidri. J Indian Soc Pedod Prev Dent 1999 Jun;17(2):45-48.

2. Willerhausen B, Haas G, Krummernauer F, Hohenfellner $\mathrm{K}$. Relationship between high weight and caries frequency in German elementary school children. Eur J Med Res 2004 Aug;9(8):400-404.

3. Kopycka-Kedzierawski DT, Auinger P, Billings RJ, Weitzman M. Caries status and overweight in 2- to 18-year-old US children: findings from national surveys. Community Dent Oral Epidemiol 2008 Apr;36(2):157-167.

4. Scientific Advisory Committee on Nutrition. Carbohydrates and health. London: The Stationary Office; 2015. Available from https://www.gov.uk/government/publications/sacncarbohydrates-and-health report.

5. Moynihan PJ, Kelly SA. Effect on caries of restricting sugars intake: systematic review to inform WHO guidelines. J Dent Res 2014 Jan;93(1):8-18.
6. Te Morenga L, Mallard S, Mann J. Dietary sugars and body weight: systematic review and meta-analysis of randomised controlled trials and cohort studies. BMJ 2013 Jan;346:e7492.

7. Locker D. Deprivation and oral health: a review. Community Dent Oral Epidemiol 2000 Jun;28(3):161-169.

8. Downs SH, Black N. The feasibility of creating a checklist for the assessment of the methodological quality both of randomised and non-randomised studies of health care interventions. J Epidemiol Community Health 1998 Jun;52(6): 377-384.

9. de Jong-Lenters M, van Dommelen P, Schuller AA, Verrips EH. Body mass index and dental caries in children aged 5 to 8 years attending a dental paediatric referral practice in the Netherlands. BMC Res Notes 2015 Dec;8:738.

10. Lempert SM, Froberg K, Christensen LB, Kristensen PL, Heitman BL. Association between body mass index and children among children and adolescents. Community Dent Oral Epidemiol 2014 Feb;42(1):53-60.

11. Sharma S, Shukla AK, Parashar P, Ahmad S, Bansal R, Varshney AM, Singh D. Association between dental caries and BMI-for age with sugar consumption among school children. Asian Pac J Health Sci 2014;1(4S):58-62.

12. Martins RJ, Moimaz SA, Silva MR, Saliba O, Garbin CA. Body mass index, dental caries and sugar intake in 2-5 year old preschoolers. Braz J Oral Sci 2014 Jul-Sep;13(3):209-212.

13. Chukwumah NM, Azodo CC, Adeghe HA, Enabulele JE. Relating dental caries experience with body mass index among Nigerian primary school children: a cross sectional survey. J Educ Ethics Dent 2012;2(1):28-32.

14. Elangovan A, Mungara J, Joseph E. Exploring the relation between body mass index, diet and dental caries among 6-12-year-old children. J Indian Soc Pedod Prev Dent 2012 Oct-Dec;30(4):293-300.

15. Cinar B, Murtomaa H. Clustering of obesity and dental health with lifestyle factors among Turkish and Finnish preadolescents. Obes Facts 2008 Aug;1(4):196-202.

16. Pinto A, Kim S, Wadenya R, Rosenberg H. Is there an association between weight and dental caries among pediatric patients in an urban dental school? A correlation study. J Dent Educ 2007 Nov;71(11):1435-1440.

17. Creske M, Modeste N, Hopp J, Rajaram S, Cort D. How do diet and body mass index impact dental caries in Hispanic elementary school children? J Dent Hyg 2013 Feb;87(1): 38-46.

18. Bagherian A, Sadeghi M. Association between dental caries and age specific body mass index in preschool children of an Iranian population. Indian J Dent Res 2013 Jan-Feb;24(1):66-70.

19. Shahraki T, Shahraki M, Mehr SO. Association between body mass index and caries frequency among Zahedan elementary school children. Int J High Risk Behav Addict 2013 Dec;2(3):122-125.

20. Cantekin K, Gurbuz T, Demirbuga S, Demirci T, Duruk G. Dental caries and body mass index in a sample of 12 year old eastern Turkish children. J Dent Sci 2012 Mar;7(1):77-80.

21. Thippeswamy HM, Kumar N, Acharya S, Pentapati KC. Relationship between body mass index and dental caries among adolescent children in South India. West Indian Med J 2011 Oct;60(5):582-586.

22. Willerhausen B, Blettner M, Kasaj A, Hohenfellner K. Association between body mass index and dental health in 1290 elementary schools in a German city. Clin Oral Investig 2007 Sep;11(3):195-200. 
23. Shailee F, Sogi GM, Sharma KR. Association between dental caries and body mass index among 12 and 15 years school children in Shimla, Himachal Pradesh. J Adv Oral Res 2013 Jan-Apr;4(1):7-13.

24. Parkar SM, Chokshi M. Exploring the association between dental caries and body mass index in public school children of Ahmedabad city, Gujarat. SRM J Res Dent Sci 2013 Nov;4(3):101-105.
25. Aykroyd, WR.; Mayer, J. Food and nutrition terminology. In: WHO Doc Nut/68.6. Geneva: WHO; 1968. p. 667.

26. Silva AE, Menezes AM, Demarco FF, Vargas-Ferreira F, Peres MA. Obesity and dental caries: systematic review. Rev Saude Publica 2013 Aug;47(4):799-812.

27. Kantovitz KR, Pascon FM, Rontani RMP, Gaviao MBD. Obesity and dental caries-a systematic review. Oral Health Prev Dent 2006 Feb;4(2):137-144. 